\title{
STABILITY OF GROUP AND RING HOMOMORPHISMS
}

\author{
DENGHUA ZHANG AND HUAI-XIN CAO
}

\begin{abstract}
In this paper, we give generalization of Hyers' theorem on the stability of approximately additive mapping and a generalization of Badora's theorem on approximate ring homomorphism. We also obtain a more general stability theorem, which gives stability theorems on Jordan and Lie homomorphisms. The proofs of the theorems given in this paper follow essentially the D. H. Hyers - Th. M. Rassias approach to stability of functional equations connected with S. M. Ulam's problem.
\end{abstract}

Mathematics subject classification (2000): 51A10, 46H99.

Key words and phrases: Stability, group homomorphism, ring homomorphism.

\section{REFERENCES}

[1] S. M. Ulam, A Collection of Mathematical Problems, Interscience, New York, 1960.

[2] D. H. HYERS, On the stability of the linear functional equation, Proc. Nat. Acad. Sci. U.S.A, 27, (1941), 222-224.

[3] TH. M. Rassias, On the stability of the linear mapping in Banach spaces, Proc. Amer. Math. Soc, 72, (1978), 297-300.

[4] R. BADORA, On approximate ring homomorphisms, J. Math. Anal. Appl, 276, (2002), 589-597.

[5] Z. GAJDA, On stability of additive mappings, Internat. J. Math. Math. Sci, 14, (1991), 431-434.

[6] D. H. Hyers, G. ISAC AND TH. M. RASSIAS, Stability of Functional Equations in Several Variables, Birkhauser, Boston, 1998.

[7] P. GaVRUTA, A generalization of the Hyers-Ulam-Rassias stability of approximately additive mappings, J. Math. Anal. Appl., 184, (1994), 431-436.

[8] C. G. PARK, On the stability of the linear mapping in Banach modules, J. Math. Anal. Appl. 275, (2002), $711-720$.

[9] TH. M. Rassias, On a modified Hyers-Ulam sequence, J. Math. Anal. Appl., 158, (1991), 106-113.

[10] TH. M. Rassias, P. SEMRL, On the Hyers-Ulam stability of linear mappings, J. Math. Anal. Appl., 173, (1993), 325-338. 